\title{
The Investigation of Working Memory in Monolinguals, Bilinguals and Trilinguals
}

\author{
Nashmineh Moradi \\ Department of ELT, Kermanshah Science and Research Branch \\ Islamic Azad University, Kermanshah, Iran \\ $\&$ \\ Department of ELT, College of Literature and Humanities \\ Kermanshah Branch, Islamic Azad University, Kermanshah, Iran \\ Tel: 98-91-8919-2325Ｅ-mail: n.moradi.uni@gmail.com \\ Hamid Gholami \\ Department of ELT, College of Literature and Humanities, Kermanshah Branch \\ Islamic Azad University, Kermanshah, Iran \\ Tel: 98-91-8131-0368Ｅ-mail: hamidgholami@iauksh.ac.ir
}

Received: May 22, 2016 Accepted: July 15, 2016 Published: August 1, 2016

doi:10.5296/jse.v6i3.9652 URL: http://dx.doi.org/10.5296/jse.v6i3.9652

\begin{abstract}
The aim of the present study was to figure out if there are any differences between monolinguals, bilinguals and trilinguals regarding their working memory capacity. This study was exposed fact in design and was a quantitative correlational study. For the purpose of this study, 90 Iranian participants were selected from different universities and foreign language institutes. For all monolingual samples Persian was their only language, for bilinguals Persian was their first language and Kurdish was their second language, and trilinguals were participants with the ability, in addition to Persian and Kurdish, to speak in English. The results of the three research questions indicated that monolinguals and bilinguals had no significant difference regarding their working memory capacity, the result was the same for monolinguals and trilinguals, but there was a significant difference between bilinguals and trilinguals in their working memory capacity.
\end{abstract}

Keywords: working memory, monolingual, bilingual, trilingual. 


\section{Introduction}

Language is one of our most articulated means that is used mainly for expressing ideas and thoughts. There is a science of language which looks at language from the perspective of "expressing ideas and thoughts". This approach to the study of language is known as the cognitive perspective. In the cognitive perspective, language is seen as part of a cognitive system which includes perception, emotions, categorization, abstraction processes, and reasoning. These cognitive abilities all interact with language and are influenced by language (Fortkamp, 2000).

During nearly every moment of our lives, we are surrounded by language. We use language to communicate our thoughts and feelings, to connect with others and identify with our culture, and to understand the world around us. For many people, this linguistic environment involves not just one language but two or more. Today, more of the world population is bilingual or multilingual than monolingual Bilingualism and multilingualism are the norm rather than the exception in today's world (Harris \& McGhee-Nelson, 1992).

People are different in their cognitive characteristics; these varieties may cause some uniqueness, and also may have some reasons. Language can be a reason. Language is assumed to have a role in the way people think or behave. It may be the source of many other differences not discovered yet. There may be also differences between monolinguals and multilinguals in terms of their cognition.

Regarding working memory there is many definitions and also some models, which are differ with each other in some way, for example Baddeley and Logie (1999) define working memory as:

"it comprises those functional components of cognition that allow human to comprehend and mentally represent their immediate environment, to retain information about their immediate past experience, and to formulate, relate, and act on current goals"(pp. 28-29). Engle (2011) defined working memory as: individual ability to storing and manipulation of information in the course of ongoing cognitive activities.

Miyake and Shah (1999) defined working memory to refers to "mechanisms or processes involved in the temporary storage, manipulation, and maintenance of task relevant information during online cognitive operations, including comprehension, and production, and general learning" (p.450).

A working memory definition that is relevant to the present study comes from the Babbeley and Hitch's (1974) seminal model of working memory, which is summarized as:

There are two essential components of the working memory system. The first is concerned with the temporary storage of information; that is, short-term memory. The second is concerned with the control of that information, as required to carry out complex tasks, and the component responsible for this is variously referred to as the central executive or central attention. (p. 427)

There have been many studies that investigated individuals' working memory capacity to find 
whether there is a connection between working memory capacity and their other skills. For example, Daneman and Green (1986) investigated whether there is any relationship between working memory capacity and the ability to produce synonyms for words presented in context. As the result, they found a correlation between working memory capacity scores and the synonym lexical test scores. Fortkamp' (2000) investigation was to experiment if working memory capacity could be regarded as a predicator of individual differences in L2 fluency, accuracy, complexity and weighted lexical density. In this study, Speaking Span Test was used to measure working memory capacity of the subjects. Results indicated that individuals with higher working memory capacity tend to be more fluent, accurate, and complex in L2. In another study, Torres (2003) studied working memory capacity and its relationship with L2 speech performance in planned and spontaneous conditions. In this research the working memory measurement instrument was Speaking Span Test (version of Daneman\& Green, 1986). The two tasks used for L2 speech performance were both "there-and-then" picture cued narratives (Robinson, 1995), the speech samples were analyzed based on fluency, accuracy, and complexity. The result of the study showed that, under spontaneous conditions, there is a significant correlation between working memory and accuracy in the performance of the control group, and at the expense of fluent and complex speech production, greater accuracy was achieved by higher spans. Based on this result, Tavares discussed that besides the significant correlations between working memory capacity and fluency, under planned condition, there was significant correlation between working memory capacity and complexity.It was also argued that the correlation between working memory capacity and performance under planned condition is the indicator of individual with higher working memory capacity, process the higher fluency and complexity.

Torres (1998) experimented the relationship among previous knowledge, L2 working memory capacity, and L2 reading comprehension. The reading span test and reading comprehension tests called free written recall was used as the measurement instruments. The result showed that because of the heavy burden of the information processing in L2 on working memory capacity, reading span of the participants was smaller, and when the domain knowledge was high, the result of the span test and reading comprehension test revealed higher scores. Torres discussed the assumption that knowledge activation can compensate the processing difficulties in L2. Torres also stated that participants' processing efficiency affects their working memory capacity and also on their comprehension abilities.

Hartsuiker and Pickering (2008) investigation was in line with the role of Working memory in online processing of syntactic relations within sentences. The result was that involvement of working memory during L2 online processing of syntax, unlike in L1, is not observed consistently. In another research by Oller and Eilers (2002) on "balancing interpretations regarding effects of bilingualism", the result was interesting. They found that students who know more than one language, have some advantages over monolinguals cognitively and in their metalinguistic ability and at the other hand monolingual students have advantages over bilingual students in linguistic expression ability (oral, grammar, and formal storytelling), but not in literacy and abstract narrative elements. They illustrated that these bilingual students linguistically have more space to search in memory as compared with monolingual students. 
Having such a purpose in mind, the following research questions were formulated:

1. Is there any significant difference between monolinguals and bilinguals in terms of their working memory capacity?

2. Is there any significant difference between monolinguals and trilinguals in terms of their working memory capacity?

3. Is there any significant difference between bilinguals and trilinguals in terms of their working memory capacity?

\section{Method}

\subsection{Design}

This study is expost facto in design and is a quantitative correlational study.

\subsection{Participants}

In this study the sample consisted of 90 Iranian participants, including; 30 monolinguals, 30 bilinguals, and 30 trilinguals (35male, 55female) selected from different university and language institutes of Kermanshah, Iran. Their age ranged between up to 15 and 40, thus predominantly adult population were studied. The reason for selecting this range was that according to Piaget (1985) the stage of cognitive development (formal operational stage) begins around 11 and is fully achieved by age 15 . All the participants had academic education in humanity. All the participants were in second, third, fourth semester of their M.A course. The detailed information about their major, age, and gender were obtained through the first page of the questionnaires. Monolingual and bilingual participants were selected from Azad University of Kermanshah, Payamenoor University of Kermanshah, and Razi University of Kermanshah.Trilingualswere selected from three language institutes (College Institute, Bamdadan Institute, and Zagros Institute). For all monolingual sample, Persian was their only language, for bilinguals, Persian was their first language and Kurdish was their second language, and trilinguals were participants with the ability, in addition to Persian and Kurdish, to speak in English. Among these three groups of people trilinguals for their proficiency of the English were screened and only those who were upper intermediate and advanced, based on the language institute hierarchy were selected. The purpose of having subjects from the same level of proficiency was to ensure that the results were not affected by differences in knowledge of the language. Monolinguals and bilinguals were screened according to their self report. Monolingual of the study were subjects who use only one language (Persian) in home and school, and bilinguals were people who use both Persian and Kurdish in home and in social context.

\subsection{Procedure}

According to Mitchell, Myles, Marsden (2013) "measures of working memory capacity need to tap into both its storage function and its processing computational function" (p. 152). So two types of procedures were used to measure participants' working memory capacity; one for measuring their visouspatial part of their working memory and the other one for 
estimating their central executive component of working memory. In other words; for the current study, both visiuospatial and verbal working memory of all participants were assessed using a storage-only task (Speaking Span Test) and a task that required both storage and processing of information (Digit Span Test). So a version of Daneman and Green's (1986) Speaking Span Test (SST) was used to measure working memory capacity of the participants. The training phase of this test contained 10 words, and the testing phase contained 40 words. The test contained 40 unrelated words that we reorganized in three sets each of two, three, four, five and six words.

Each of these words was presented individually, on the middle line of a laptop and remained for a second. Before starting the test the participants were instructed to read each word loudly. At the end of each set of these words, there was a question mark that means it is the time that participants use the presented words in the exact form and order they appeared to generate grammatically correct sentences. Participants were told that there were no restrictions on the produced sentences, but they should be syntactically and semantically acceptable. After finishing a given set of the words; the next set was presented, and this procedure was followed until all sets were presented. The maximum number of words participants could make grammatical sentences was regarded as their speaking span score. The reliability and validity of the test were reported by Engle (1989) to be acceptable.

As the second task participants were presented with a Digit Span Test. Digit is one of the most commonly used measures of immediate verbal recall. In this task the participants were exposed to a large amount of numbers. It comprised two modalities, Digit Forward and Digit Backward. During the task a series of strings of digits were read to subjects, and then they were asked to repeat them orally in the correct sequence (either forward or backward). The number of digits in each string increased from 2 to 9 forward and 2 to 8 backward. If the subject fails two consecutive trails, the test was discontinued. Total score corresponds to the maximum number of digits the participants were able to repeat correctly.

Baddeley(2000) argued that Digit Span Tests implicate verbal working memory. In this task, forward digit span is managed primarily by the phonological loop, but when the digits are repeated in the reverse order, it is expected that more extensive involvement of central executive occurs, as the number strings have to be remembered and then reversed in order to give the correct answer. So in this task both the central executive and the phonological loop of working memory are engaged.

\subsection{Data Analysis}

To answer the related research questions, the normality of the distribution of the data was computed using SPSS, as the normal distribution of the data which was computed in Kolmogrov Smirnov was not confirmed so for comparing the means of the working memory and all monolingual, bilingual, and trilingual groups nonparametric Mann-Whitney test was used, which is the equal of the parametric independent sample t-test.

\section{Results}

The first research question was: 


\section{Macrothink}

Q1: Is there any significant difference between monolinguals and bilinguals in terms of their working memory capacity?

In order to answer this research question, working memory of both monolingual and bilingual groups was assessed using the Speaking Span Test and the Digit Span Test, the final score was the sum of the scores of these two tests. The statistical description of both monolingual and bilingual's working memory scores has been provided in Table 1 which is as follows:

Table 1. Descriptive Statistics of Working Memory Test

\begin{tabular}{lccccc}
\hline & $\mathrm{N}$ & Minimum & Maximum & Mean & Std. Deviation \\
\hline Working & 88 & 12.00 & 29.50 & 21.1818 & 2.93921 \\
Valid N (listwise) & 88 & & & & \\
& & & & & \\
\hline
\end{tabular}

In Table 1 , the mean score was 21.18 and standard deviation was 2.93 . The minimum score was 12.00 and the maximum was 29.50 .

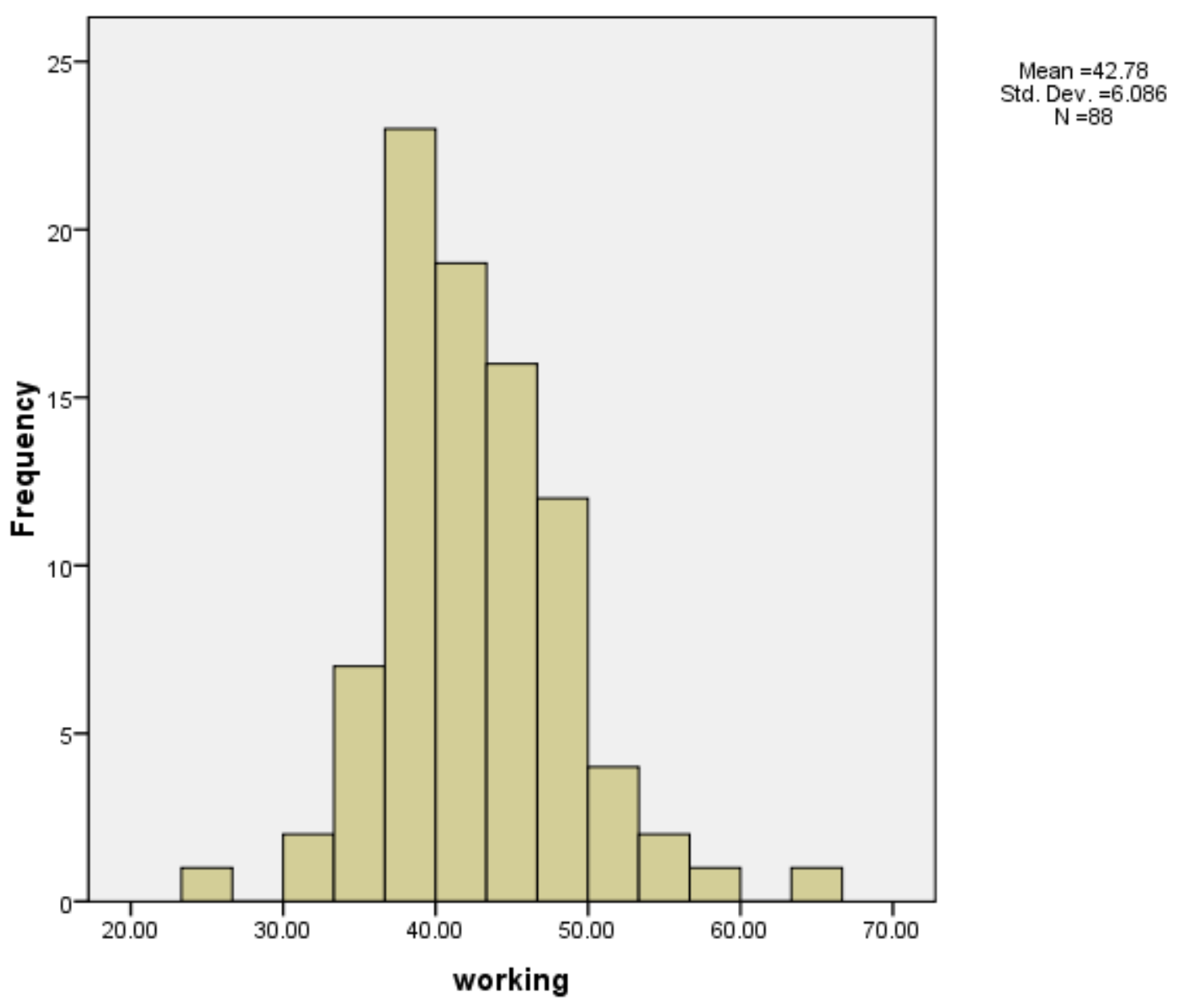

Figure 1. the working memory scores 


\section{Macrothink}

The above figure shows the participants working memory scores and the frequency of each score. In the following Table the ranks of the monolingual and bilingual's working memory scores has been presented.

Table 2. Ranks ofThe Monolingual and Bilinguals’ Working Memory Scores

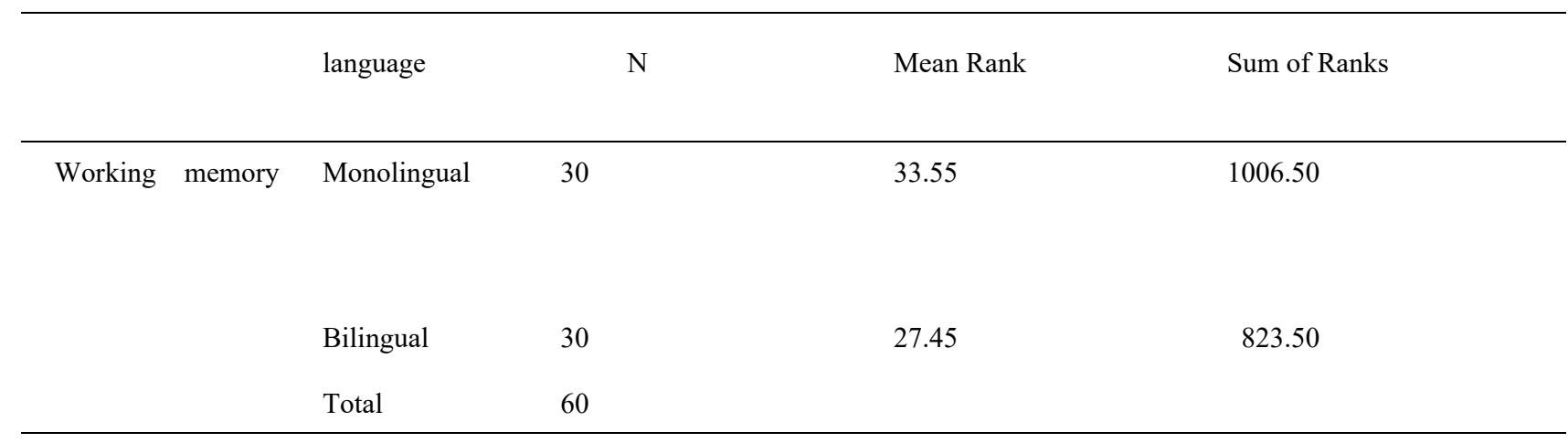

As it has been showed in Table 4.2 the mean rank of monolingual participants has been reported 33.55, and that of bilingual participants was 27.45. The sum of ranks was 1006.50 and 823.50 , for monolinguals and bilinguals, respectively.

The following Table deals with comparing the means of the score of both monolinguals and bilinguals' working memory scores:

Table 3. Mann-Whiteny Test of Working Memory Scores of the Monolinguals and Bilinguals

\begin{tabular}{lc}
\hline & Working memory \\
\hline Mann-Whitney U & 358.500 \\
Wilcoxon W & 823.500 \\
Z & -1.358 \\
Asymp. Sig. (2-tailed) & .174 \\
\hline
\end{tabular}

a. Grouping Variable: language

The finding of Table 4.3 revealed that $Z=-1.358$ and $U=358.50$ and as the sig $(.174)>0.05$ the first research hypothesis is accepted and showed no significant difference between working memory capacity of monolinguals and bilinguals of the study.

Second research question aim was to compare monolinguals and trilinguals differences, if any, in their working memory capacity. The descriptive rank Table of monolinguals and trilinguals was presented. 
Table 4. Ranks of the Monolingual and Trilinguals' Working Memory Scores

\begin{tabular}{|c|c|c|c|c|}
\hline & language & $\mathrm{N}$ & Mean Rank & Sum of Ranks \\
\hline \multirow[t]{3}{*}{ Working memory } & Monolingual & 30 & 26.25 & 787.50 \\
\hline & trilingual & 28 & 32.98 & 923.50 \\
\hline & Total & 58 & & \\
\hline
\end{tabular}

According to above Table the mean rank of monolinguals with $\mathrm{N}=30$ was 26.25 and the mean rank of trilingual participants with $\mathrm{N}=29$ was reported as 32.98 , monolingual's sum of ranks was 787.50 and that of trilinguals was 923.50. Comparing the working memory scores of monolingual and trilingual groups was also computed by Mann-Whitney Test. The following Table shows the results.

Table 5. Mann-Whitney Test of Working Memory Scores of the Monolinguals and trilinguals

\begin{tabular}{ll}
\hline & Working memory \\
\hline Mann-Whitney U & .500 \\
Wilcoxon W & 787.500 \\
Z & -1.522 \\
Asymp. Sig. (2-tailed) & .128 \\
\hline
\end{tabular}

a. Grouping Variable: language

This Table showed that $Z=-1.52$ and $U=322.50$ and as the $\operatorname{sig}(.128)>0.05$ the second research hypothesis was accepted and indicates no significant difference between working memory capacity of monolinguals and trilinguals of the study.

The third research question was:

Is there any significant difference between bilinguals and trilinguals in terms of their working memory capacity?

The third research question addressed the comparison between bilinguals and trilinguals in their working memory capacity. Below the rank Table of this comparison is provided: 
Table 6. Ranks of the Bilingual and Trilingual's Working Memory Scores

\begin{tabular}{|c|c|c|c|c|}
\hline & language & $\mathrm{N}$ & Mean & Sum of Ranks \\
\hline \multirow[t]{3}{*}{ Working memory } & bilingual & 30 & 24.03 & 721.00 \\
\hline & trilingual & 28 & 35.36 & 990.00 \\
\hline & Total & 58 & & \\
\hline
\end{tabular}

In the above Table bilingual's $\mathrm{N}=30$, mean rank $=24.03$, and sum of ranks $=721.00$, on the other hand trilingual's $\mathrm{N}=28$, mean rank $=35.36$, and sum of ranks $=990.00$.

Table 7 showed the results of Mann-Whitney Test which was used for comparing working memory of bilinguals and trilinguals.

Table 7. Mann-Whitney Test of Working Memory Scores of Bilinguals and Trilinguals

\begin{tabular}{lc}
\hline & Working memory \\
\hline Mann-Whitney U & 256.000 \\
Wilcoxon W & 721.000 \\
Z & -2.559 \\
Asymp. Sig. (2-tailed) & .011 \\
\hline
\end{tabular}

a. Grouping Variable: language

The results of the table implied that $U=256.00$, and $Z=-2.55$, and as $\operatorname{sig}(.011)<0.05$, it showed that there is a significant difference between bilingual and trilinguals in terms of their working memory capacity. So the hypothesis based on the lack of existence of any significant differences between bilinguals and trilinguals in their working memory capacity ( hypothesis 3) was not confirmed.

\section{Discussion}

This study was set to verify whether language is a factor that exerts influence on working memory capacity of individuals. As it was mentioned before the sample was an adult population, and to the best of my knowledge there is no study investigating cognitive characteristic differences of adults, but the results of the current study was in line with Engle (2011) who found no advantages of being bilingual in working memory over monolinguals, considering the fact that the sample of her study was children. The finding of this study also was not in line with Oller and Eilers (2002) who illustrated that bilingual students have more space to search in memory as compared with monolingual students, although the sample of their study was bilinguals who learned the second language rather than acquired it and this 
may yield different results. Engle (2011) failed to find bilinguals' visuospatial working memory advantages over monolinguals. The result of the present study confirms the finding of her study. It worth to be noted that although bilingualism is defined as the ability to speak two languages, but learning the second language is different from acquiring it. So maybe one of the reason that the result of this study may not confirmed the results of the other studies, (regardless of the age, gender, education, etc) is that, bilingualism is not a single concept, and there are various types of bilingualism, for example a bilingual person who is a native speaker in one language and is capable of understanding but not speaking another one is different from a person who is more or less equally proficient in both languages. Therefore it is better first to consider the type of bilingualism, and then make a comparison between the results of different studies.

\section{Conclusion}

This study was set to verify whether language is a factor that exerts influence on working memory capacity as well as attention control ability of individuals. Based on the results of this study it can be concluded that monolinguals and bilinguals had no significance difference regarding their working memory capacity, the finding was the same for monolinguals and trilinguals but it was a significant difference between bilinguals and trilinguals in terms of their working memory capacity. Therefore, based on the results obtained from the comparison between bilinguals and trilinguals of the study, it can be concluded that language can be regarded as a factor that may affect cognitive characteristics (here working memory capacity) of individuals, and that knowing more than one language even in adults may cause some differences in some of their cognitive characteristics. And as all other characteristics of the samples was almost in the same level, such as their academic education, their age, their field in education, etc, so it can be concluded that it was the language that caused such an effect in working memory of this two groups of the sample.

\section{References}

Baddeley, A. D (2000). The Episodic Buffer: A New Component of Working Memory? Trends in Cognitive Science, 4, 417-423. http://dx.doi.org/10.1016/S1364-6613(00)01538-2

Baddeley, A. D., \& Logie, R. H. (1999). The multiple-component model. Models of workingmemory: Mechanisms of active maintenance and executive control, 28-61. http://dx.doi.org/10.1017/CBO9781139174909.005

Daneman, M., \& Green, I. (1986).Individual differences in comprehending and producing words in context. Journal of Memory and Language, 25, 1-18. http://dx.doi.org/10.1016/0749-596X(86)90018-5

Engle, R. W., Nations, J. K., \& Cantor, J. (1990). Is" working memory capacity" just another name for word knowledge?Journal of Educational psychology, 82(4), 799. http://dx.doi.org/10.1037/0022-0663.82.4.799

Engle, R.W., \& Shipstead, Z., Redick, T. S. (2012). Is working memory training effective? Psychological bulletin, 138(4), 628. http://dx.doi.org/10.1037/a0027473 
Fortkamp, M. B. M. (2000). Working memory capacity and L2 speech production: An exploratory study. Unpublished Ph.D. dissertation, Federal University of Santa Catarina, Florianópolis, Santa Catarina, Brazil.

Harris, R. J., \& Nelson, E. M. M. (1992). Bilingualism: Not the exception any more. Advances in psychology, 83, 3-14. http://dx.doi.org/10.1016/S0166-4115(08)61485-5

Hartsuiker, R. J., \& Pickering, M. J. (2008). Language integration in bilingual sentence production. ActaPsychologica, 128(3), 479-489. http://dx.doi.org/10.1016/j.actpsy.2007.08.005

Mitchell, R., Myles, F., \& Marsden, E. (2013). Second language learning theories. Routledge.

Miyake, A., \& Shah, P. (1999). Toward unified theories of working memory: Emerging general consensus, unresolved theoretical issues, and future research directions. In A. Miyake, \& P. Shah (Eds.), Models of working memory: Mechanisms of active maintenance and executive control (pp. 442-481). New York: Cambridge University press. http://dx.doi.org/10.1017/CBO9781139174909.016

Oller, D. K., \& Eilers, R. E. (Eds.). (2002). Language and literacy in bilingual children (Vol. 2).Multilingual Matters.

Piaget, J. (1985). The equilibration of cognitive structures: The central problem of intellectual development. University of Chicago Press.

Robinson, P. (1995). Task complexity and second language narrative discourse. Language Learning, 45(1), 99-140. http://dx.doi.org/10.1111/j.1467-1770.1995.tb00964.x

Torres, A. C. G. (1998). Prior Knowledge, L2 working memory capacity, and L2 reading comprehension: How do they relate? Unpublished Master's thesis, Federal University of Santa Catarina, Florianópolis. 